\title{
ARTIGO
}

\section{Abordagem sistêmica para investigar trágico acidente marítimo no Brasil}

\author{
Systemic approach to investigate tragic marine accident in Brasil \\ Anastácio Pinto Gonçalves Filho' \\ Palmério Silva Queiroz ${ }^{2}$
}

RESUMO: O presente trabalho apresenta o resultado de uma investigação de acidente marítimo em que foi utilizada a abordagem sistêmica, na qual o sistema como um todo é considerado, e o acidente descrito como resultante de uma relação descontrolada de suas partes constituintes. Para isso, foi utilizado como método de investigação o Accimap. O acidente investigado ocorreu no estado da Bahia, quando uma embarcação, conhecida como Cavalo Marinho I, que realizava o transporte de passageiros entre os terminais marítimos de Salvador e Mar Grande, na Ilha de Itaparica, naufragou e resultou na morte de 19 pessoas. Sendo considerada a pior tragédia envolvendo o transporte marítimo no estado. Na fase de coleta de dados, foram entrevistados os tripulantes e o proprietário da embarcação. Também foram realizadas análises de documentos e inspeções nos terminais marítimos e em embarcações similares à sinistrada. Além disso, foi feita uma travessia entre os terminais com o comandante da Cavalo Marinho I. Um mapa do acidente foi construído, constando 13 fatores sistêmicos que contribuíram para a ocorrência e a inter-relação entre eles. Recomendações foram apresentadas com o objetivo de melhorar a segurança do sistema do transporte marítimo, como, por exemplo, a dragagem e a desobstrução do canal marítimo de acesso ao atracadouro da Praia Mar Grande. Conclui-se que a abordagem sistêmica permitiu desenvolver um quadro completo de como e por que o acidente ocorreu, além de recomendar medidas apropriadas para prevenir a sua recorrência.

\footnotetext{
1 Engenheiro mecânico, engenheiro de segurança do trabalho, mestre em engenharia ambiental, doutor em engenharia industrial, todos pela Universidade Federal da Bahia (UFBA), pós-doutorado na Universidade de Loughborough, Reino Unido. É Professor do curso de engenharia de produção da UFBA e Auditor-Fiscal do Trabalho. E-mail: anastafilho@ufba.br

2 Graduado em Administração pela União Pioneira de Integração Social, especializado em Planejamento e Administração de Recursos Humanos pela Associação de Ensino Unificado do Distrito Federal. É Auditor-Fiscal do Trabalho. E-mail: palmerio.queiroz@mte.gov.br
} 
Palavras-chave: abordagem sistêmica; acidente; investigação; marítimo.

ABSTRACT: This article presents the result of a maritime accident investigation where the systemic approach was used, in which the system as a whole is considered and the accident described as resulting from an uncontrolled relation of its constituent parts. For this, Accimap investigation method was used. The accident occurred in the state of Bahia, when a ship known as Cavalo Marinho I, which carried passengers between the maritime terminals of Salvador and Mar Grande, on the Island of Itaparica, sank and resulted in the deaths of 19 people. Being considered the worst tragedy involving shipping in the state. In the data collection phase, the crew and the owner of the ship were interviewed. There were also analyzes of documents and inspections at the maritime terminals and in vessels similar to those reported. In addition, a crossing was made between the terminals with the commander of Cavalo Marinho I. A map of the accident was constructed, containing 13 contributing factors and the interrelationship between them. Recommendations were presented with the aim of improving the safety of the maritime transport system, such as dredging of the maritime access channel to Mar Grande Beach. It is concluded that the systemic approach allowed to develop a complete picture of how and why the accident occurred and to recommend appropriate measures to prevent that similar accident occurs again.

Keywords: accident; investigation; marine; systemic approach.

\section{INTRODUÇÃO}

Acidentes de trabalho constituem-se um problema de saúde pública em todo o mundo, por serem potencialmente fatais, incapacitantes, e acometerem, em especial, pessoas jovens e em idade produtiva, levando a um grande impacto sobre a produtividade e a economia. No Brasil, morrem, em média, 2.600 trabalhadores, anualmente, vítimas de acidentes, considerando apenas o setor formal da economia (BRASIL, 2017).

Mensurar as perdas com os acidentes envolve uma equação complexa, pois uma parcela das perdas é intangível (como a perda da vida, mudança na vida e na atividade de trabalho do acidentado, impactos na vida da família e diminuição de sua qualidade de vida), que não é possível quantificar (WEIL, 2001). No entanto, essas perdas devem e podem ser prevenidas.

Nesse contexto, a investigação de acidentes é um importante meio para ajudar a entender como eles ocorrem, identificar os fatores contribuintes que levaram ao sinistro e propor medidas apropriadas para a prevenção de novos acidentes no futuro (SALMON; CORNELISSEN; TROTTER, 2012). No entanto, uma investigação de 
acidentes deve seguir um método, pois este é essencial para o entendimento de como o acidente ocorreu (LUNDBERG; ROLLENHAGEN; HOLLNAGEL, 2009).

Cada método, porém, tem diferentes áreas de aplicação, qualidade e deficiências. Eles também diferem entre si em relação à base teórica, tipo de representação dos fatores contribuintes e os resultados que produzem (SKLET, 2004).

Sistemas sociotécnicos são aqueles caracterizados pela interação entre fatores humanos e tecnológicos, isto é, entre elementos tais como equipamentos, sistemas informatizados, processos físicos, pessoas, procedimentos, leis e regulações (BRANFORD, 2011). Eles são constituídos por diferentes partes, incluindo o processo de produção, os operadores, supervisores e gestores, que interagem entre si para atingir aos objetivos.

Os sistemas sociotécnicos são abertos, ou seja, podem ser afetados pelas ações do governo e por leis e políticas regulatórias relativas à atividade do setor (REASON, 1997). Além disso, os sistemas sociotécnicos são considerados complexos quando envolvem grande quantidade de pessoas e componentes que se juntam para fazê-los funcionar. Esse tipo de sistemas requer comunicação e coordenação de pessoas de diferentes culturas, disciplinas e localização geográfica (RASMUSSEN, 1997).

$\mathrm{Na}$ abordagem sistêmica, é considerado o sistema como um todo e descrito o acidente como resultante de uma relação descontrolada de suas partes constituintes. Esse tipo de abordagem surgiu no final dos anos 1990 e reflete o aumento de complexidade dos sistemas sociotécnicos, que apresentam uma diversidade de fatores contribuintes para um acidente.

O objetivo deste trabalho é apresentar os resultados de uma investigação de acidente marítimo no qual foi utilizada a abordagem sistêmica. Para isto, foi selecionado um método de investigação conhecido como Accimap.

Não foram encontrados, na literatura, estudos nos quais fosse utilizada uma abordagem sistêmica, ou aplicado um método que possibilitasse esse tipo de abordagem para investigar acidentes ocorridos na atividade de transporte marítimo, no Brasil. No entanto, a literatura científica internacional apresenta a aplicação do Accimap para investigar acidentes ocorridos nessa atividade. Como exemplo, citamse Lee et al. (2016) e Kee et al. (2016), que aplicaram esse método para investigar um acidente envolvendo um Ferry ocorrido na Coreia do Sul. 
Assim, o estudo apresentado aqui pode ser considerado como o primeiro no país, utilizando a abordagem sistêmica em investigação de acidentes marítimos, como também o uso do Accimap para este tipo de evento.

\section{MÉTODO}

O acidente investigado neste trabalho ocorreu no dia 24 de agosto de 2017, nas proximidades do Terminal Marítimo de Vera Cruz, Ilha de Itaparica/BA, que resultou na morte de 19 passageiros, quando uma embarcação de nome Cavalo Marinho I naufragou durante a travessia entre a cidade de Mar Grande e a cidade de Salvador/BA.

\section{SELEÇÃO DO MÉTODO DE INVESTIGAÇÃO DE ACIDENTE}

O método Accimap, sigla de Accident Map, que significa, na língua portuguesa, Mapa do Acidente, em livre tradução, foi desenvolvido por Rasmussen (1997) e é utilizado nas abordagens sistêmicas de investigação de acidentes.

Para a aplicação do método, os seguintes níveis são analisados: 1. Governo (inclui executivo, legislativo e judiciário); 2. Corpo regulatório (inclui órgãos do governo responsáveis pela fiscalização); 3. Gestão da organização; 4. Gestão técnica e operacional; 5. Processo físico e 6. Equipamentos e ambiente. São identificados fatores que contribuíram para o acidente em cada um desses níveis, bem como a inter-relação entre eles.

Branford (2011), no entanto, propôs um Accimap modificado ou padrão, no qual quatro níveis são analisados em vez de seis, porém sem perder a natureza de abordagem sistêmica do método. Os quatro níveis propostos foram os seguintes: nível 1: Externo, que inclui governo e corpo regulatório; nível 2: Organização, que inclui gestão da empresa, técnica e operacional; nível 3: processo físico, equipamentos e ambiente; e nível 4: consequências do acidente.

Neste trabalho foi selecionado o Accimap modificado proposto por Branford (2011). A seleção ocorreu pela abordagem sistêmica que proporciona, como também por ser mais prático e fácil de usar, além de atender à complexidade de acidentes marítimos.

\section{COLETA DE DADOS}

A primeira fase da investigação do acidente consistiu basicamente na coleta de informações, tendo como base o método Accimap, como mencionado anteriormente. Para isto, foram utilizadas as fontes descritas a seguir. 
A tripulação da embarcação que sofreu o acidente, incluindo o comandante, foi entrevistada. Como todos os membros da equipe sobreviveram ao naufrágio, foram importantes fontes para relatar, em detalhes, como o sinistro ocorreu, como foram feitos o pedido de socorro e o resgate dos passageiros.

Outros tripulantes e comandantes de embarcações semelhantes à sinistrada e que realizam a mesma travessia também foram ouvidos, com a finalidade de identificar fatores diferentes, que pudessem ter contribuído para o acidente, além daqueles apresentados pela tripulação sobrevivente.

Também foi entrevistado o proprietário e armador da embarcação com o objetivo de buscar informações com relação à gestão técnica e operacional da empresa capaz de ter influenciado para que o acidente ocorresse.

Buscando identificar fatores externos à empresa, situados no nível 1 do Accimap, foram entrevistados os responsáveis pelos órgãos de fiscalização.

No caso específico da travessia onde ocorreu a tragédia, existem dois órgãos fiscalizadores. Um de âmbito federal, aqui chamado de Autoridade Marítima, responsável pela fiscalização da segurança da navegação, determinando, por exemplo, o número de tripulantes e o treinamento oferecido a eles, além da quantidade máxima de passageiros, entre outros itens relacionados à segurança na navegação.

E o outro órgão é pertencente ao governo do estado da Bahia, chamado de Agência de Regulação, que é responsável por fiscalizar a qualidade dos serviços prestados pelas empresas que realizam o transporte marítimo aos usuários do sistema, como por exemplo, o cumprimento de horários previstos, preços de passagens e conforto de embarcações utilizadas no transporte.

Outras fontes de informação que se buscou foram as documentais. Neste sentido, foram analisados documentos apresentados pela empresa proprietária da embarcação, os quais foram objeto de notificação, prevista na legislação trabalhista em vigor.

Também foram solicitados documentos de competência dos dois órgãos de fiscalização já mencionados. Essa documentação foi disponibilizada mediante requerimento formal dirigida a essas instituições.

Em complemento, foram utilizadas reportagens apresentadas na imprensa escrita e falada, bem como aquelas publicadas nas redes sociais. A veracidade das informações constantes nestas fontes foi previamente checada antes de serem utilizadas. 
Uma inspeção nos terminais marítimos, que fazem parte da travessia, foi realizada, com o objetivo de identificar fatores presentes nestes locais que contribuíram para o ocorrido. Igualmente foram inspecionadas as embarcações que realizam a travessia e que eram similares a Cavalo Marinho I.

Não foi possível inspecionar a embarcação acidentada, porque depois do acidente ela foi levada pela correnteza e chocou-se contra arrecifes existentes próximos à praia. Em consequência disso, ficou destruída e sem condições de ser examinada.

Por fim, os auditores-fiscais do trabalho, responsáveis pela investigação, realizaram a travessia com o comandante da embarcação da Cavalo Marinho I no momento do acidente. Para isto, foi utilizada uma embarcação similar à sinistrada.

Durante a travessia, o comandante relatou o que ocorreu em cada ponto do trajeto até o instante da tragédia. Desta forma, foi possível dirimir as dúvidas e esclarecer os fatos.

A segunda fase da investigação constituiu na análise dos dados coletados na fase anterior. Não necessariamente as duas fases tiveram uma delimitação nítida, mas, muitas vezes, correram em paralelo. Quando havia dúvida durante a análise de alguns dados ou foi identificada a necessidade de mais informações, foi inevitável que mais dados fossem coletados.

$\mathrm{Na}$ terceira fase da investigação foi construído o Accimap ou Mapa do Acidente, no qual foram colocados os fatores identificados em cada nível.

\section{RESULTADOS E DISCUSSÃO}

Com base nos dados coletados, foram produzidos os resultados apresentados adiante.

\section{SOBRE A TRAVESSIA}

Cabe ao Estado da Bahia, conforme estabelecido em lei estadual (BAHIA, 2011), explorar diretamente, ou mediante concessão ou permissão, os serviços de transporte hidroviários intermunicipal de passageiros.

Está incluída nesses serviços a travessia de passageiros entre o Terminal Marítimo de Salvador e o Terminal Marítimo de Vera Cruz, conhecida popularmente como travessia Salvador/Mar Grande. 
Mar Grande é a praia onde está instalado o Terminal Marítimo de Vera Cruz, município situado na Ilha de Itaparica.

Em março de 2012, o estado da Bahia, com o objetivo de atender ao estabelecido em lei estadual, licitou por edital a concessão de serviços de transporte hidroviário metropolitano de passageiros entre o Terminal Marítimo de Salvador e o Terminal Marítimo de Vera Cruz, que já era realizada sem concessão desde a década de 1950. Naquela década, eram apenas pequenos barcos que tinham o objetivo de transportar moradores dos dois municípios da ilha (Itaparica e Vera Cruz) até a capital, Salvador.

As duas empresas outorgadas com a concessão para a operação das linhas Salvador/ Mar Grande/Salvador ficaram obrigadas, conforme o edital, a efetuar os investimentos necessários à melhoria da qualidade dos serviços prestados aos usuários, responsabilizando-se pela modernização da frota, através da incorporação de novas embarcações tipo catamarã.

No entanto, o investimento em novas embarcações estava condicionado à realização, por parte do Poder Concedente, no caso o estado da Bahia, dos serviços de dragagem e desobstrução do canal marítimo de acesso ao atracadouro da Praia Mar Grande, em Vera Cruz.

Até o término da conclusão da investigação do acidente, os serviços de dragagem e desobstrução do canal marítimo não foram iniciados, consequentemente, as empresas concessionárias não realizaram investimento em novas embarcações como previsto no edital de licitação.

As embarcações utilizadas pelas empresas concessionárias dos serviços de transporte Salvador/Mar Grande são as mesmas que já estavam operando antes da concessão, todas de casco de madeira e antigas, entre elas a Cavalo Marinho I.

Segundo levantamentos efetuados pelo órgão estadual de fiscalização dos serviços, para a travessia Salvador/Mar Grande, no ano de 2011, era prevista uma demanda de 4.000 passageiros/dia, chegando a 10.000 passageiros/dia no período de alta estação.

A distância entre os dois terminais é de $10,06 \mathrm{~km}$ e o tempo máximo de viagem determinado no edital é de 40 minutos.

\section{EMBARCAÇÃO ENVOLVIDA NO ACIDENTE}

A embarcação Cavalo Marinho I tinha casco de madeira e comprimento de 18,64 m. Possuía dois conveses para o transporte de passageiros. O convés superior era coberto 
e aberto nas laterais. O convés inferior era também coberto, mas fechado nas laterais e tinha apenas uma via de acesso, uma escada no centro da embarcação. $O$ convés superior comportava 89 passageiros e o inferior 71, totalizando 160 passageiros.

A embarcação estava autorizada a realizar a atividade de transporte na travessia de passageiros entre o Terminal Marítimo de Salvador e o Terminal Marítimo de Vera Cruz/Ilha de Itaparica no estado da Bahia.

A análise de documentos revelou que a Cavalo Marinho I estava adequadamente tripulada no momento do acidente, com uma tripulação constituída pelos seguintes membros: um comandante, um chefe de máquinas, um marinheiro de máquinas e um marinheiro de convés. Todos estavam regularmente treinados e com seus documentos atualizados.

\section{DESCRIÇÃO DO ACIDENTE}

Às 6h30min do dia 24/08/2017, a lancha Cavalo Marinho I parte do Terminal Marítimo de Vera Cruz, na Ilha de Itaparica, com destino Salvador, com 120 pessoas a bordo (116 passageiros e 4 tripulantes).

Por volta das 6h35min, ela passa por um farol existente no canal da praia de Mar Grande.

Cinco minutos após passar pelo farol, às 6h40min, na altura de um banco de areia, a embarcação é atingida por uma onda no lado direito, em relação ao rumo da navegação (estibordo).

O comandante, pressentindo a tragédia, gritou: "vai virar, vai virar Jorginho [outro tripulante]". A lancha realmente virou, não totalmente, mas o suficiente para lançar os passageiros e tripulantes ao mar, e causar grande desespero.

"A lancha não virou totalmente, ela ficou assim, deitada. Foi tudo muito rápido", explicou.

Não foi possível pedir socorro pelo rádio, pois a cabine da embarcação ficou alagada, explicou o comandante.

Às 7h40min, quase uma hora depois que a lancha naufragou, chegaram as primeiras embarcações para o resgate das vítimas.

Até aquele instante, os tripulantes e os passageiros lutavam para salvar suas vidas e de outros, conforme relatou o comandante "[...] quando o socorro chegou, foi umas $7 \mathrm{~h} 40 \mathrm{~min}$. O momento de resgate foi intenso. A Cavalo Marinho III foi enviada ao 
local e começamos a colocar as pessoas, depois chegou a Santa Maria [lancha]. Em seguida, chegou um catamarã de Salvador, a terceira embarcação a chegar, que foi de ótima ajuda porque é um barco mais baixo e agilizou o resgate".

No entanto, 19 pessoas não conseguiram ser salvas.

A Cavalo Marinho I não afundou, mas ficou à deriva e encalhou nos arrecifes existentes próximos da praia.

\section{MAPA DO ACIDENTE - ACCIMAP}

A figura 1 apresenta o Accimap construído para o acidente com a Cavalo Marinho I.

Constata-se que 13 fatores contribuintes para o acidente foram identificados, sendo dois no Nível 1, quatro no Nível 2, cinco e dois fatores nos Níveis 3 e 4, respectivamente. Assim, o maior número de fatores identificados se encontra no âmbito da empresa.

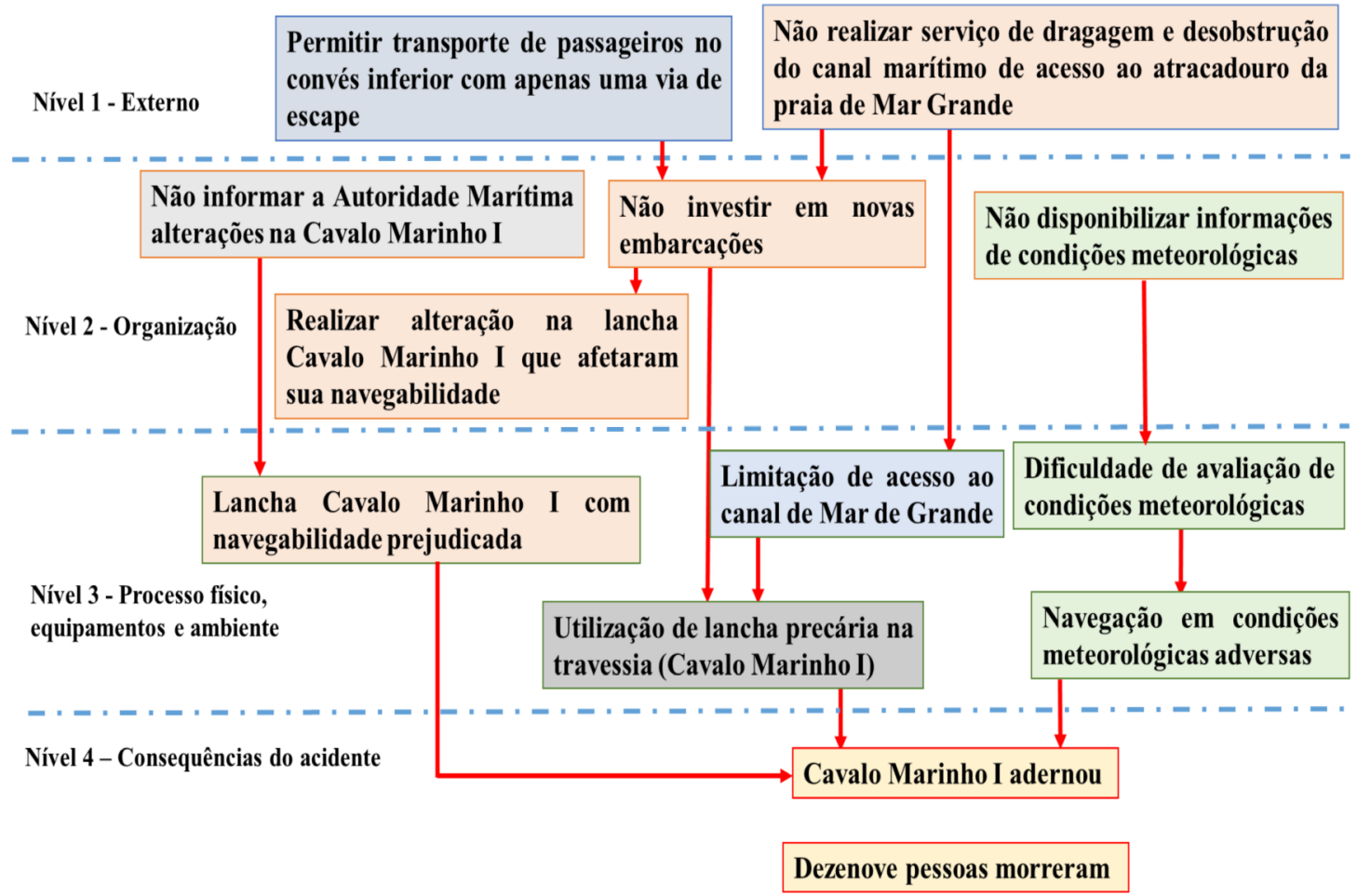

Figura 1 - Mapa do acidente Accimap 
No Accimap, também é possível observar a inter-relação entre os fatores localizados em diferentes níveis. As setas ligando os fatores situados em níveis distintos significam que houve influência do fator do nível superior para que aquele no nível mais abaixo ocorresse.

Assim, o fator descrito como Não realizar serviço de dragagem e desobstrução do canal marítimo de acesso ao atracadouro da praia Mar Grande, localizado no Nível 1 (externo), contribuiu para que o fator Não investir em novas embarcações, que se encontra no Nível 2 (organização), acontecesse. Este fator, por sua vez, contribuiu para a ocorrência da Utilização de lancha precária (Cavalo Marinho I), que está no Nível 3 (processo físico, equipamentos e ambiente). A utilização de uma lancha precária, como era a Cavalo Marinho I, favoreceu para ela adernasse, ocasionando a tragédia.

As demais inter-relações entre os fatores podem ser seguidas pelo leitor no Accimap.

\section{FATORES DO NÍVEL 1 - EXTERNOS}

Como exposto previamente, os fatores identificados nesse nível estão relacionados ao governo e corpo regulatório.

Um dos fatores relacionados ao acidente, situado no âmbito externo do Accimap, foi o Permitir transporte de passageiros no convés inferior da lancha Cavalo Marinho I com apenas uma via de escape. A Normam 2, norma da Autoridade Marítima, estabelece que em qualquer embarcação com arqueação bruta $(\mathrm{AB})$ maior que 50 (a lancha Cavalo Marinho I tinha $\mathrm{AB}$ igual a76), deverá haver, pelo menos, duas vias de escape amplamente separadas em todos os níveis de acomodações, de compartimentos de serviço ou da praça de máquinas.

Considerando que a lancha Cavalo Marinho I nunca foi impedida de transportar passageiros no convés inferior, embora este não possua duas vias de escape, conforme descrito acima, a empresa continuou utilizando a lancha, sem promover as necessárias adequações ou investir em outras embarcações. É possível que essa condição tenha contribuído até para o aumento do número de vítimas.

$\mathrm{O}$ outro fator verificado no nível externo foi Não realizar serviço de dragagem e desobstrução do canal marítimo de acesso ao atracadouro da praia Mar Grande. A modernização da frota ficou condicionada ao serviço de dragagem e desobstrução do canal de acesso ao atracadouro da praia de Mar Grande, que não foi feito. Portanto, a não realização desse serviço desobrigou que as empresas concessionárias do serviço 
de travessia Salvador/Mar Grande investissem em novas embarcações (catamarãs) maiores, com mais conforto e mais seguras do ponto de vista da navegação.

\section{FATORES DO NÍVEL 2 - ORGANIZAÇÃO}

Aqui são descritos os fatores relacionados com a organização, no caso a empresa proprietária da embarcação Cavalo Marinho I. Um dos fatores constados foi Realizar alterações na Cavalo Marinho I que afetaram sua navegabilidade. Segundo reportado na imprensa local, o Inquérito Administrativo Sobre Acidentes e Fatos da Navegação (IAFN), realizado pela Autoridade Marítima para apurar as causas do acidente, identificou que a concessionária fez alterações na lancha Cavalo Marinho I, logo após a vistoria intermediária, realizada no dia 20/04/2017, que afetaram sua navegabilidade, contribuindo para que a lancha naufragasse.

A Autoridade Marítima, explicou que "a embarcação não cumpria os critérios de estabilidade exigidos por lei. A embarcação possuía lastros não autorizados e colocados de forma indevida que acabaram se soltando. Faltava fixá-los no local correto. Conseguimos calcular que os pesos desses lastros chegam a até $400 \mathrm{~kg}$ ”.

Isso significa que foram instalados lastros (pesos) na embarcação para melhorar sua navegabilidade. No entanto, esses lastros, formados por pedras (paralelepípedos), foram instalados incorretamente, o que prejudicou a estabilidade da embarcação.

Outro fator situado no Nível 2 foi Não informar à Autoridade Marítima as alterações realizadas na lancha Cavalo Marinho I. Essas alterações referem-se à instalação de lastro na embarcação. Segundo reportado na imprensa local, no mesmo IAFN citado acima, foi identificado que a concessionária não solicitou a Licença de Alteração à Autoridade Marítima, quando instalou lastro de pedra na lancha, o que afetou a sua navegabilidade. A solicitação da Licença de Alteração é obrigatória, conforme estabelecido pela Normam 2.

Ainda, segundo a Autoridade Marítima: "para se instalar os pesos e os lastros existe todo um procedimento. É preciso que se contrate um engenheiro responsável técnico para que acompanhe e apresente à Marinha essas alterações pedindo uma licença de alteração e isso não foi cumprido".

Quando uma embarcação passa por uma alteração, deverá ser cancelado o seu Certificado de Segurança de Navegação (CSN), documento expedido pela Autoridade Marítima que autoriza a embarcação a navegar, e providenciada a realização de nova 
vistoria inicial e, após o cumprimento das exigências, porventura existentes, será emitido um novo Certificado.

Acontece que a lancha Cavalo Marinho I passou por alterações que não foram comunicadas à Autoridade Marítima. Assim sendo, não passou por nova vistoria. Consequentemente, seu CSN estava cancelado, portanto, estava realizando a travessia Salvador Mar Grande de forma irregular.

Um terceiro fator contribuinte para o sinistro situado no âmbito da organização foi Não investir em novas embarcações. Apesar de estarem desobrigadas de investirem em novas embarcações, tipo catamarã, conforme previsto no edital que trata da licitação da concessão do serviço de transporte de travessia Salvador/Mar Grande, pela não realização por parte do estado da Bahia, dos serviços de dragagem e desobstrução do canal marítimo de acesso ao atracadouro da Praia Mar Grande, em Vera Cruz/BA, o edital, citado acima, estabelece que as lanchas deveriam ter cabines protegidas contra intempéries, como por exemplo, proteção contra chuva, vento e respingos de ondas, o que não era atendido pela Cavalo Marinho I.

Finalmente, o quarto fator nesse nível foi Não disponibilizar informações de condições meteorológicas. Ficou evidenciado no curso da investigação que as empresas concessionárias não disponibilizam informações sobre as condições meteorológicas para os comandantes das embarcações, ficando sob a responsabilidade destes buscá-las de fontes diversas e decidir se realizavam ou não a travessia.

No dia do acidente não havia "Aviso de mau tempo" emitido pela Autoridade Marítima. Além disso, três lanchas (5h, 5h30min e 6h) já tinham partido, sem intercorrências ocasionadas por condições adversas do tempo.

Embora o comandante tenha o poder de decidir pela realização ou não da travessia, ele toma suas decisões sob pressão, não explícitas, da empresa, da Agência de Regulação e dos usuários do sistema.

Diante desse cenário, o comandante decidiu partir com a lancha Cavalo Marinho I, às 16h30min, meia hora depois da lancha anterior ter partido. Cinco minutos depois (6h $35 \mathrm{~min}$ ), após o farol e próximo ao banco de areia, foi surpreendido com chuvas e vento fortes. Incontinenti, foi atingido por uma onda forte, que ocasionou o naufrágio da lancha, dez minutos após a partida (6h40min).

\section{FATORES DO NÍVEL 3 - PROCESSO FÍSICO, EQUIPAMENTO E AMBIENTE}


Os fatores identificados nesse nível são consequência dos fatores situados nos dois níveis anteriores.

Assim, eles estão, fundamentalmente, relacionados às condições de trabalho inadequadas e à precariedade da embarcação que sofreu o acidente. Acrescentam-se, ainda, as condições ambientais adversas no dia do desastre.

Deste modo, a Utilização de lancha precária na travessia (Cavalo Marinho I) foi um dos fatores detectados nesse nível. A lancha Cavalo Marinho I, embora apta para realizar a travessia, era uma lancha pequena, antiga (de 1973), com apenas um acesso para o convés inferior e não protegia os passageiros contra a chuva e o vento satisfatoriamente. No momento do acidente, alguns passageiros foram para o mesmo lado da embarcação por causa da chuva, conforme inúmeros depoimentos.

No dia do acidente, ela substituiu outra lancha, chamada Nossa Senhora da Penha, que estava em manutenção, segundo informou em seu depoimento o comandante.

Ele relatou aos Auditores-Fiscais do Trabalho: “[...] se fosse um catamarã ou um barco três vezes mais largo resistiria ao mau tempo".

Uma sobrevivente fez o seguinte relato à mídia local sobre a lancha Cavalo Marinho I: "A embarcação (Cavalo Marinho I) é a pior possível que existe. Para você ter uma ideia, quando ela está encostada lá, no normal, já fica toda torta. Muita gente teve a sorte que não veio. Eu mesma ia desistir quando eu vi que era a Cavalo Marinho I. Eu pensei: não vou. Ficou mais ou menos oito ou nove pessoas que quando viu que era a Cavalo Marinho desistiu porque é a pior embarcação que tem".

Ressalta-se que as embarcações pertencentes à empresa proprietária da Cavalo Marinho tinham, em 2017, ano do naufrágio, em média, 24 anos, sendo que a Cavalo Marinho I contava com quase o dobro dessa média.

Um fator identificado nesse nível que evidencia a precariedade das condições de trabalho foi a Dificuldade de avaliação das condições meteorológicas por parte dos comandantes das embarcações.

Isso acontece porque as empresas, como já descrito, não disponibilizam informações sobre as condições meteorológicas para os comandantes, que ficam com a responsabilidade de buscar informações e decidir pela travessia. Esse fator pode propiciar a má avaliação de condições meteorológicas por parte do comandante. 
Essa situação pode ser evidenciada pelo fato de o comandante realizar a Navegação em condições meteorológicas adversas, o que contribuiu para o acidente. Isso porque ele não tinha meios apropriados para avaliar adequadamente as condições de tempo.

Finalmente, a Limitação de acesso ao canal da praia de Mar Grande foi um fator incluído nesse nível por ser um fator concernente ao ambiente.

O canal da praia de Mar de Grande, no município de Vera Cruz, por ser raso, com pouca profundidade, não permite a navegação de lanchas maiores, com calado e largura maiores, do que as que já realizam a travessia atualmente. Essa situação inviabiliza o investimento por parte das concessionárias em lanchas de maior porte, como já relatado neste artigo.

\section{FALHAS SISTÊMICAS}

A maioria das falhas sistêmicas que contribuiu para o acidente, apresentada neste artigo, está sob a responsabilidade da empresa proprietária da embarcação que tem o intuito de identificá-las e solucioná-las. Um exemplo de um desses fatores é Não investir em novas embarcações e colocar em operação equipamentos modificados, sem segurança e não vistoriados.

No entanto, foram identificados fatores contribuintes que estavam além do controle da organização. Como por exemplo, aqueles relacionados a processos governamentais, como a fiscalização da segurança da embarcação e ações que deveriam ser executadas para a melhoria do sistema do transporte marítimo.

Para exemplificar, cita-se o fator Não realizar serviço de dragagem e desobstrução do canal marítimo de acesso ao atracadouro da praia Mar Grande como uma falha sistêmica localizada no âmbito de governo.

Esses fatores evidenciam que as inadequações na área governamental também têm o potencial de prejudicar a segurança do sistema e ocasionar resultados adversos. Portanto, é essencial considerar essa área ao investigar os fatores que podem contribuir para tragédias.

É importante ressaltar que, embora os órgãos governamentais sejam responsáveis por fiscalizar e monitorar as atividades de organizações de um determinado setor, eles, muitas vezes, não têm estrutura ou força suficiente para exercer essa responsabilidade. 
Por isso, essa situação leva a atuações ineficientes desses órgãos. Desta forma, condições perigosas podem permanecer dentro de sistemas sociotécnicos, contribuindo para os acidentes.

\section{APLICAÇÃO DO ACCIMAP}

Esse artigo apresentou a aplicação do método Accimap para coletar e analisar os fatores contribuintes para o acidente com a Cavalo Marinho I, uma das piores tragédias do transporte marítimo no país.

Uma importante característica do método Accimap é colocar os eventos e as condições que contribuíram para o acidente em diferentes níveis de responsabilidade, para permitir a compreensão de como e por que ele ocorreu (BRANDORF, 2007). Essa característica evita imputar injustamente a culpa aos trabalhadores da linha de frente, uma vez que proporciona uma perspectiva geral dos níveis onde se originaram os fatores contribuintes para o evento sinistro (SALMON et al., 2011).

Essa característica utilizada no contexto da investigação da estragédia com a embarcação Cavalo Marinho I possibilitou não considerar somente os fatores imediatos ao evento, tampouco as condições ou as decisões e ações tomadas pela tripulação do embarque no dia do acidente, como as causas que contribuíram para essa tragédia, mas também investigar o papel e a contribuição de fatores em níveis mais elevados da empresa e dos elementos externos, como, por exemplo, o papel dos órgãos fiscalizadores.

Em outras palavras, o Accimap permitiu que os investigadores identificassem fatores situados nos âmbitos organizacional, governamental e órgãos regulatórios, ou seja, buscasse identificar todos os fatores dentro dos diferentes níveis propostos pelo método, conforme apresentado na figura 1.

Outra característica importante do Accimap é destacar as interações dos fatores entre os níveis do método. Desta forma, é possível analisar e identificar inter-relações entre os níveis, que contribuíram para o acidente (WATERSON et al., 2016).

Assim, o método possibilitou construir um retrato mais abragente do acidente, quando comparado com outros métodos tradicionais de investigação de acidentes. Isto é, mostrou que os fatores contribuintes para ele ocorrer não estavam somente no nível dos tripulantes, das conditições ambientais e dos equipamentos, mas também se encontravam nos níveis mais elevados e nas inter-relações entre esses fatores. 
No entanto, o Accimap apresenta algumas desvantagens na sua aplicação. Salmon et al. (2011) citam, por exemplo, que devido à abrangência do método, a qualidade dos resultados produzidos dependente muito dos dados levantados durante o processo de investigação. Além disso, o tempo gasto no levantamento desses dados é demorado e nem sempre eles estão disponíveis ou são difíceis de encontrar no nivel externo (governo, legislação, agência de regulação e fiscalização).

Durante a investigação do acidente com a Cavalo Marinho I, essas desvantagens foram encontradas, mas superadas, principalmente pelo fato de os investigadores serem auditores fiscais do trabalho, assim, com acesso a informações de órgãos públicos e da empresa envolvida no acidente.

\section{VANTAGENS DA ABORDAGEM SISTÊMICA}

Esse trabalho mostrou que a investigação de acidentes com a perspectiva da abordagem sistêmica concentra-se no contexto e nas circunstâncias em que o comportamento dos trabalhadores ocorreu, e não nos erros cometidos por eles. Essa abordagem trabalha com a suposição de que os seres humanos são falíveis e que essa falibilidade pode ser evitada até certo ponto, mas não pode ser eliminada por completo (GONÇALVES FILHO et al., 2019).

Além disso, a partir da abordagem sistêmica, reconhece-se que o comportamento das pessoas dentro de sistemas complexos é afetado por fatores externos, como regras, procedimentos e controles gerenciais, administrativos e regulatórios (BEVILACQUA; CIARAPICA, 2018). Desta forma, o contexto sistêmico, no qual os erros humanos são cometidos, deve ser levado em conta para entender como e por que os acidentes ocorrem.

A partir dessa perspectiva, os acidentes são vistos como sendo o resultado de cenários e falhas no sistema que levam aos acidentes.

Além de destacar as causas sistêmicas, esse enfoque amplia o entendimento dos fatores de riscos envolvidos na história do acidente, pois fornece uma compreensão de como o sistema se comportou e como ele não conseguiu lidar com as falhas existentes. Essa compreensão é perdida se uma abordagem centrada no indivíduo for adotada.

O objetivo da investigação nessa perspectiva, portanto, é descobrir como e por que o sistema falhou e não conseguiu evitar que ele resultasse em acidente (BRANFORD, 2007). 
Por isso, a abordagem sistêmica é atualmente reconhecida como a mais apropriada para compreender um acidente (SALMON et al., 2011).

Atualmente, existe uma crescente percepção de que os fatores sistêmicos podem afetar a segurança do sistema. Assim sendo, ações de prevenção devem ser tomadas no sentido de atuar sobre os fatores de tais eventos (WATERSON et al., 2016).

Nesse sentido, as medidas propostas para prevenir que acidentes semelhantes ocorram concentram-se em agir sobre as falhas do sistema que induzem aos acidentes. Além disso, garantir que as defesas do sistema para preveni-los sejam bemsucedidas (GOODE et al, 2017).

Isso porque é reconhecido que as correções destinadas a abordar essas inadequações do sistema têm efeitos consideravelmente maiores e mais duradouros sobre a segurança do que os esforços direcionados ao comportamento dos indivíduos (UNDERWOOD; WATERSONU, 2014).

Ademais, os tipos de problemas levantados pela abordagem sistêmica geralmente têm amplos efeitos negativos sobre os sistemas, com o potencial de contribuir para vários tipos diferentes de acidentes (LEVESON, 2007).

Assim, descobrir e reparar esses problemas sistêmicos pode, portanto, ajudar a evitar uma série de possíveis acidentes futuros, em vez de apenas uma recorrência de um tipo específico.

Portanto, esforços destinados a abordar fatores sistêmicos são mais benéficos para a segurança do sistema como um todo do que tentativas de minimizar e prevenir erros humanos específicos.

\section{RECOMENDAÇÕES}

A formulação das recomendações é uma fase importante da investigação, pois estas visam propor ações que evitem que acidentes semelhantes voltem a ocorrer ou minimizem suas consequências.

Elas devem ser resultantes das falhas identificadas no sistema como um todo, que contribuíram para o acidente, como também daquelas contribuintes para seu agravamento. 
Desse modo, as seguintes recomendações foram propostas para a prevenção de acidentes envolvendo embarcações que fazem a travessia Salvador/Mar Grande, bem como para a melhoria do sistema de transporte marítimo.

Como um dos principais empecilhos para investimento em embarcações de maior porte pelas empresas concessionárias, foi recomendado que o serviço de dragagem e desobstrução do canal marítimo de acesso ao atracadouro da Praia Mar Grande fosse realizado.

Nada impede, porém, que seja exigida pela Agência Estadual de Regulação a substituição, de imediato, das atuais embarcações que estão sendo operadas na travessia Salvador/Mar Grande por outras modernas, que ofereçam conforto e segurança aos usuários e tripulantes.

Caso essa exigência não seja atendida, que sejam cancelados ou não prorrogados os contratos vigentes de concessão de linha da travessia Salvador/Mar Grande.

Caso isso aconteça, seja realizada uma nova concorrência de concessão dos serviços, para possibilitar a entrada no sistema de novas empresas com embarcações mais modernas.

Outra recomendação, caso as empresas não se disponham a adquirir novas embarcações com as características já citadas, seria o próprio Estado adquiri-las e disponibilizá-las para as empresas concessionárias, semelhante ao que acontece no sistema Ferry Boat, que faz a travessia Salvador/Ilha de Itaparica.

Já no âmbito da Autoridade Marítima, foi recomendado que seja observado o que estabelece a Normam 2 , que determina que em qualquer embarcação com $\mathrm{AB}$ maior que 50 (a lancha Cavalo Marinho I tinha $\mathrm{AB}$ igual 76), deverá haver, pelo menos, duas vias de escape amplamente separadas em todos os níveis de acomodações, de compartimentos de serviço ou da praça de máquinas.

Para evitar a demora nos pedidos de socorro, a recomendação é que sejam disponibilizadas lanchas apropriadas para o atendimento de emergência, que possam se deslocar com rapidez e chegar ao local do sinistro no menor tempo possível.

Recomendou-se, ainda, que fiscalizações periódicas, além daquelas previstas nas normas marítimas, sejam realizadas para constatar possíveis irregularidades e modificações nas embarcações que realizam transporte marítimo. 
Por último, duas recomendações foram direcionadas às empresas concessionárias dos serviços de transporte de travessia Salvador/Mar Grande.

A primeira foi haver a substituição das atuais embarcações que estão sendo operadas na travessia Salvador/Mar Grande por outras modernas, que ofereçam conforto e segurança aos usuários e tripulantes.

Quanto à segunda, foi no sentido de que haja disponibilização de informações de condições meteorológicas para os comandantes das embarcações.

Em complemento, recomendou-se a criação de um comitê gestor permanente paritário formado por representantes da sociedade (usuários), do poder público e das empresas para tomar decisões sobre a operação, fiscalização, concessão e embargo das concessionárias dos serviços de transporte marítimo.

\section{CONCLUSÃO}

Este artigo apresentou uma gama de condições e problemas que ocorreram dentro do sistema de transporte marítimo entre Salvador/Mar Grande no estado da Bahia, considerado aqui como um sistema sociotécnico complexo, que degradou sua segurança, tornando-o suscetível a acidentes.

Para identificar e entender esses fatores sistêmicos, assim chamados por estarem relacionados aos sistemas sociotécnicos complexos, foi utilizada uma abordagem sistêmica. Para isto, foi selecionado como método de investigação o Accimap.

Após a construção do Accimap, ficou evidente que o acidente foi resultado de uma série de fatores em todo o sistema sociotécnico, fatores estes que interagiram de maneira que permitissem que o controle sobre os perigos fossem perdidos.

Conclui-se, assim, que a abordagem sistêmica permitiu desenvolver um quadro completo de como e por que o acidente ocorreu e recomendar medidas apropriadas para prevenir a sua recorrência.

Por último, a utilização do método de investigação Accimap mostrou-se uma apropriada técnica para identificar fatores sistêmicos que contribuem para acidentes.

Espera-se que com esta investigação, em que foi utilizada uma abordagem sistêmica, as lições do acidente sejam aprendidas e contribuam para prevenir tragédias similares. 


\section{REFERÊNCIAS}

Bahia. Lei Estadual $n^{\circ} 12.044$, de 04 de janeiro de 2011. Dispõe sobre o Sistema de Transporte Hidroviário Intermunicipal de Passageiros e Veículos do Estado da Bahia - SHI, e dá outras providências. Publicado no Diário Oficial do Estado em 04 de Janeiro de 2011.

Bevilacqua, M.; Ciarapica, F. E. (2018). Human factor risk management in the process industry: A case study. Reliability Engineering and System Safety, v. 169, p. 149-159.

Branford, K. (2007). An Investigation into the Validity and Reliability of the Accimap Approach. PhD Thesis. Canberra: Australian National University.

Branford, K. (2011). Seeing the big picture of mishaps: applying the Accimap approach to analyse system accidents. Aviation Psychology and Applied Human Factors, v. 1, n. 1, p. 31-37.

Brasil. Ministério da Previdência e Assistência Social. Anuário estatístico de acidentes de trabalho. Brasília, DF, 2017, v.1, p. 1-990.

Gonçalves Filho, A. P.; Souza, C. A.; Siqueira, E. L. B.; Souza, M. A.; Vasconcelos, T. P. (2019). An analysis of helicopter accident reports in Brazil from a human factors perspective. Reliability Engineering and System Safety, v. 183, p. 39-46.

Goode, N.; Salmon, P. M.; Taylor, N. Z.; Lenné, N. G.; Finch, C. F. (2017) Developing a contributing factor classification scheme for Rasmussen's Accimap: Reliability and validity evaluation. Safety Science, v. 64, p. 14-26.

Kee, D.; Jun, G. T.; Waterson, P. E.; Haslam, R. (2016). A systemic analysis of South Korea Sewol Ferry accident - Striking a balance between learning and accountability. Applied Ergonomics, p. 1-13.

Lee, S.; Moh, Y. B.; Tabibzadeh, M.; Meshkati, N. (2016). Applying the Accimap methodology to investigate the tragic Sewol Ferry accident in South Korea. Applied Ergonomics, p. 1-9.

Leveson, N. (2004). A new accident model for engineering safer systems. Safety Science, v. 42, p. 237-270. 
Lundberg, J.; Rollenhagen, C.; Hollnagel, E. (2009). What-You-Look-For-Is-WhatYou-Find - The consequences of underlying accident models in eight accident investigation manuals. Safety Science, v. 47, p. 1297-1311.

Rasmussen, J. (1997). Risk management in a dynamic society: a modeling problem. Safety Science, v. 27, n. 2, p. 183-213.

Reason, J. (1997). Managing the risks of organizational accidents. Inglaterra: Ashgate Publishing Limited.

Salmon, M. P.; Stanton, N. A. ; Lenne, M. ; Jenkins, D. P. ; Laura. R.; Walker, G. H. (2011). Human Factors Methods and Accident Analysis: Practical Guidance Case Study Applications. Surrey: Ashgate.

Salmon, P.; Cornelissen, M.; Trotter, M. J. (2004). Systems based analysis methods: a comparison of Accimap, HFACS and STAMP. Safety Science, v. 50, p. 1158-1170.

Sklet, S. Comparison of some selected methods for accident investigation. Safety Science, v. 111, p. 29-37.

Underwood, P.; Waterson, P. E. (2014). Systems thinking, the Swiss Cheese Model and accident analysis: A comparative systemic analysis of the Grayrigg train derailment using the ATSB, Accimap and STAMP models. Accident Analysis and Prevention, v. 68, p. 75-94.

Waterson, P. E.; Jenkins, D. P.; Salmon, P. M.; Underwood, P. (2016). 'Remixing Rasmussen': The evolution of Accimaps within systemic analysis. Applied Ergonomics, v. 59, p. 483-503.

Weil, D. (2001). Valuing the economic consequences of work injury and illness: a comparison of methods and findings. American Journal of Industrial Medicine, v. 40, p. $418-437$.

Recebido: 28/04/2019

Revisado: $24 / 05 / 2019$

Aprovado: 27/09/2019 